\title{
A Sensitive Carbon Dioxide Sensor Based on Photoacoustic Spectroscopy with a Fixed Wavelength Quantum Cascade Laser
}

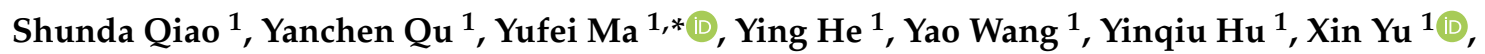 \\ Zhonghua Zhang ${ }^{1}$ and Frank K. Tittel ${ }^{2}$ (D) \\ 1 National Key Laboratory of Science and Technology on Tunable Laser, Harbin Institute of Technology, \\ Harbin 150001, China; 18S021047@stu.hit.edu.cn (S.Q.); quyanchen@hit.edu.cn (Y.Q.); \\ hearkenyi@hit.edu.cn (Y.H.); 1162100203@hit.edu.cn (Y.W.); 1162100119@stu.hit.edu.cn (Y.H.); \\ yuxin0306@hit.edu.cn (X.Y.); zhzhang@hit.edu.cn (Z.Z.) \\ 2 Department of Electrical and Computer Engineering, Rice University, 6100 Main Street, \\ Houston, TX 77005, USA; fkt@rice.edu \\ * Correspondence: mayufei@hit.edu.cn; Tel.: +86-451-86413161
}

Received: 17 September 2019; Accepted: 24 September 2019; Published: 26 September 2019

\begin{abstract}
A photoacoustic spectroscopy (PAS) based carbon dioxide $\left(\mathrm{CO}_{2}\right)$ sensor with a fixed wavelength quantum cascade laser (FW-QCL) was demonstrated. The emission wavelength of the FW-QCL at $4.42 \mu \mathrm{m}$ in the mid-infrared spectral region matched a fundamental $\mathrm{CO}_{2}$ absorption line. Amplitude modulation of the laser intensity was used to match the resonant photoacoustic (PA) cell. The noise from the background was reduced with the correlation demodulation technique. The experimental results showed that the sensor had excellent signal stability and a concentration linear response. When the integration time was $1 \mathrm{~s}$, a $1 \sigma$ minimum detection limit (MDL) of 2.84 parts per million (ppm) for $\mathrm{CO}_{2}$ detection was achieved. The long-term stability of the sensor was evaluated by means of an Allan deviation analysis. With an integration time of $\sim 100 \mathrm{~s}$, the MDL was improved to $1 \mathrm{ppm}$. This sensor was also used to measure the $\mathrm{CO}_{2}$ concentration from some common emission sources, such as cigarette smoking, automobile exhaust, and the combustion of some carbon-containing materials, which confirmed the stability and robustness of the reported FW-QCL based $\mathrm{CO}_{2}$-PAS sensor system.
\end{abstract}

Keywords: photoacoustic spectroscopy; carbon dioxide detection; quantum cascade laser

\section{Introduction}

Carbon dioxide $\left(\mathrm{CO}_{2}\right)$ is a colorless and odorless gas and is one of the main greenhouse gases. With the increasing use of fossil fuel combustion and emissions from automobile exhaust, the $\mathrm{CO}_{2}$ concentration in the atmosphere has increased from 280 parts per million by volume (ppmv) to $\sim 400$ ppmv since the industrial revolution [1,2]. The greenhouse effect has led to global warming, glacier melting, and a rise in sea levels [3,4]. If the $\mathrm{CO}_{2}$ concentration increases even further, these phenomena will become worse and affect people's life severely in the future. In addition, the high concentration of $\mathrm{CO}_{2}$ also reduces the pondus hydrogenii $(\mathrm{PH})$ of oceans and soil which impacts marine organisms and plants $[5,6]$. Therefore, there is a need to develop a sensitive $\mathrm{CO}_{2}$ gas sensor to monitor $\mathrm{CO}_{2}$ concentrations.

In 1880, Bell reported the photoacoustic effect, when he discovered that when thin discs were irradiated with modulated light, an acoustic signal is produced [7]. Subsequently, many applications based on the photoacoustic effect were developed and photoacoustic spectroscopy (PAS) has become one of the most important examples [8-10]. PAS is widely used to detect trace gases because of its 
advantages, such as high detection sensitivity, fast response time, and a wide dynamic range [11-15]. The main principle of the PAS technique is to use a modulated laser to stimulate the target gas molecules. The gas molecules absorb the optical energy from the photons and are excited. Subsequently these molecules relax to the ground state by a non-radiative process which produces localized heat. This heat results in gas expansion, which increases the local pressure. With a modulated laser, the local temperature will change periodically and a pressure wave, which is the acoustic signal, is produced. This acoustic signal can be detected with a sensitive microphone detector and used to determine the gas concentration [16-18]. Many trace gases detection methods based on PAS have already been demonstrated [19-27].

The mid-infrared spectral region is the fundamental absorption spectral band for many molecules. This means that the absorption intensity in the mid-infrared region is the strongest in the entire absorption spectrum [28]. Therefore, a laser source with an emission wavelength located in the mid-infrared region improves the sensor's detection sensitivity. A quantum cascade laser (QCL), which was invented in 1994 [29], is an attractive laser source for a trace gas sensing system based on PAS. The spectral range of a QCL can cover the entire mid-infrared region. Based on the luminescence mechanism of the QCL one electron can emit many photons, which is advantageous for producing a high optical power [30]. The commercial sensors based on QCL have the advantages of high selectivity compared with the ones based on thermal micro electro mechanical system (MEMS) emitters and non-resonant PA cell with MEMS microphones [31-35]. Therefore, the QCL based PAS sensors have excellent performance and application prospects [36].

In this paper, a sensitive PAS-based $\mathrm{CO}_{2}$ trace gas sensor was demonstrated. The excitation source was a fixed wavelength QCL (FW-QCL) emitting at $4.42 \mu \mathrm{m}$. A resonant photoacoustic (PA) cell together with a central cylinder tube was used as an acoustic resonator. Two buffers were placed at both sides of the cylinder to reduce the noise from the gas flow. The PAS signal was detected with a condenser microphone. In order to modulate the laser optical intensity a chopper was applied. A correlation demodulation technique was used in order to reduce the noise from the background. The long-term stability of the sensor system was evaluated with an Allan deviation analysis. Reliable and robust operation of the PAS sensor was demonstrated by continuous monitoring of atmospheric $\mathrm{CO}_{2}$ concentration levels. The sensor was also used to detect the $\mathrm{CO}_{2}$ concentration levels from cigarette smoking; automobile exhaust; and the combustion of paper, cable sheaths, as well as timber demonstrating that the reported mid-infrared sensor had an excellent operating performance with a potential in real world applications.

\section{Experimental Setup}

\section{1. $\mathrm{CO}_{2}$ Absorption Line Selection}

With the excellent tunability of the QCL in the mid-infrared region, it is possible to select a fundamental $\mathrm{CO}_{2}$ molecular absorption line. According to the HITRAN 2016 database [37], at a temperature of $300 \mathrm{~K}$, the $\mathrm{CO}_{2}$ absorption lines located at $\sim 4.4 \mu \mathrm{m}$ at standard atmospheric pressure are shown in Figure 1. It can be seen that an absorption line located at a wavelength of $4415.11 \mathrm{~nm}\left(2264.95 \mathrm{~cm}^{-1}\right)$ is one of the strong absorption lines. Furthermore, this line avoids $\mathrm{H}_{2} \mathrm{O}$ interference at $\sim 4.4 \mu \mathrm{m}$. 


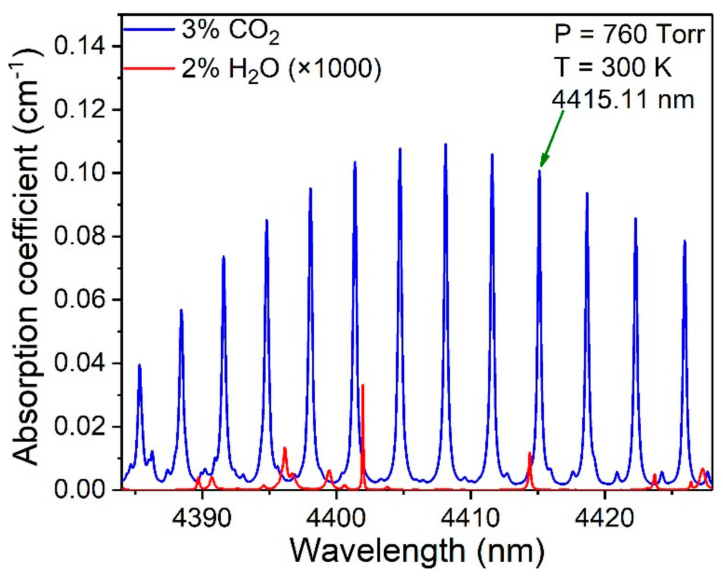

Figure 1. Absorption lines for $3 \% \mathrm{CO}_{2}$ and $2 \% \mathrm{H}_{2} \mathrm{O}$ in the $\sim 4.4 \mu \mathrm{m}$ spectral region based on the HITRAN 2016 database.

\subsection{QCL Performance Characteristics}

The excitation source of the $\mathrm{CO}_{2}$-PAS sensor system was a fixed wavelength QCL (FW-QCL, Model No. 41045-UF, Daylight Solutions), in which the laser was tuned to the desired wavelength by means of a diffraction grating. The output power of the FW-QCL can be increased by varying the injection current. The laser power as a function of injection current is shown in the Figure 2a. From this figure it can be seen that when the injection current was $500 \mathrm{~mA}$, the output power was $35.2 \mathrm{~mW}$. The wavelength of the FW-QCL was determined with a wavelength meter which has a resolution of $0.2 \mathrm{pm}$ (Model No. 721A, Bristol). The results of these measurement are shown in Figure 2b. As shown in Figure 2b, the laser central wavelength was $4415.11 \mathrm{~nm}$ when the output power was $35.2 \mathrm{~mW}$, which was a good match for the selected $\mathrm{CO}_{2}$ absorption line. The signal-to-noise ratio (SNR) of the laser emission spectrum was $\sim 20 \mathrm{~dB}$.

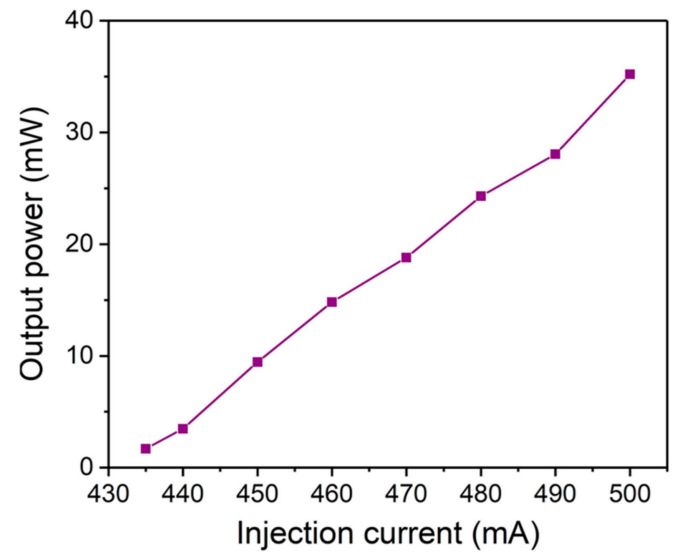

(a)

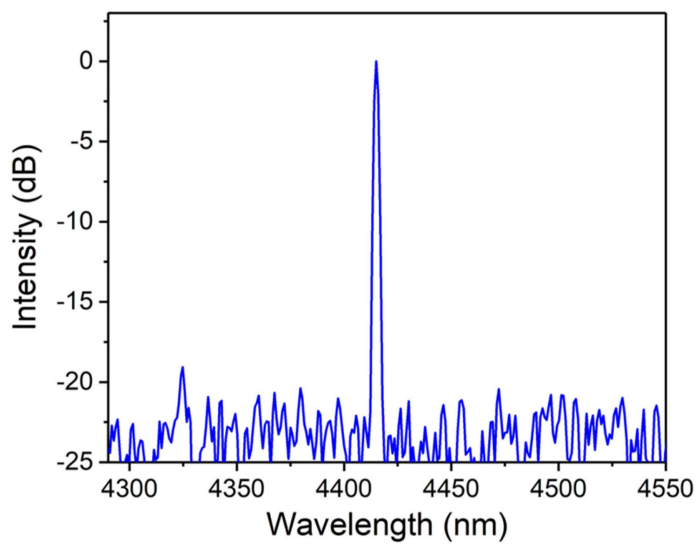

(b)

Figure 2. (a) The fixed wavelength quantum cascade laser (FW-QCL) output power as a function of at injection current. (b) The emission spectrum of the FW-QCL with a $35.2 \mathrm{~mW}$ optical power.

\subsection{Sensor System Configuration}

The schematic of the PAS based $\mathrm{CO}_{2}$ sensor system is shown in Figure 3. A resonant PA cell was used in this system which had two calcium fluoride $\left(\mathrm{CaF}_{2}\right)$ window mirrors and a central cylinder tube made of aluminum. This tube was used as the acoustic resonator and operated in a one-dimensional resonant mode. The resonant frequency was $1580 \mathrm{~Hz}$. The radius and length of the acoustic resonator were $5 \mathrm{~mm}$ and $100 \mathrm{~mm}$, respectively. To reduce the noise from the gas flow, two buffers were placed at both ends of the cylinder tube. The radius and length of the buffer were $25 \mathrm{~mm}$ and $50 \mathrm{~mm}$, 
respectively. Therefore, the total length of the PA cell was $200 \mathrm{~mm}$. A condenser microphone with detection sensitivity of $50 \mathrm{mV} / \mathrm{Pa}$ was placed inside the PA cell to detect the acoustic signal generated from the target gas. The FW-QCL operated in a continuous wave $(\mathrm{CW})$ mode. A mechanical chopper was placed between the laser and PA cell to modulate the optical intensity. The modulation frequency of the chopper was set equal to the resonant frequency of the resonator to obtain the strongest PAS signal. In order to vary the target gas concentrations, two mass flow controllers with a mass flow uncertainty of $3 \%$ were used to dilute a $30,000 \mathrm{ppm} \mathrm{CO}_{2}-\mathrm{N}_{2}$ gas mixture with pure $\mathrm{N}_{2}$. The flow rate was controlled at $120 \mathrm{ml} / \mathrm{min}$. The signal from the microphone was then sent to a lock-in amplifier. The lock-in amplifier employed a correlation demodulation technique to reduce the noise from the background. The constant time of the lock-in amplifier was $1 \mathrm{~s}$. The final detected signal was displayed on a laptop computer using the lock-in amplifier software interface.

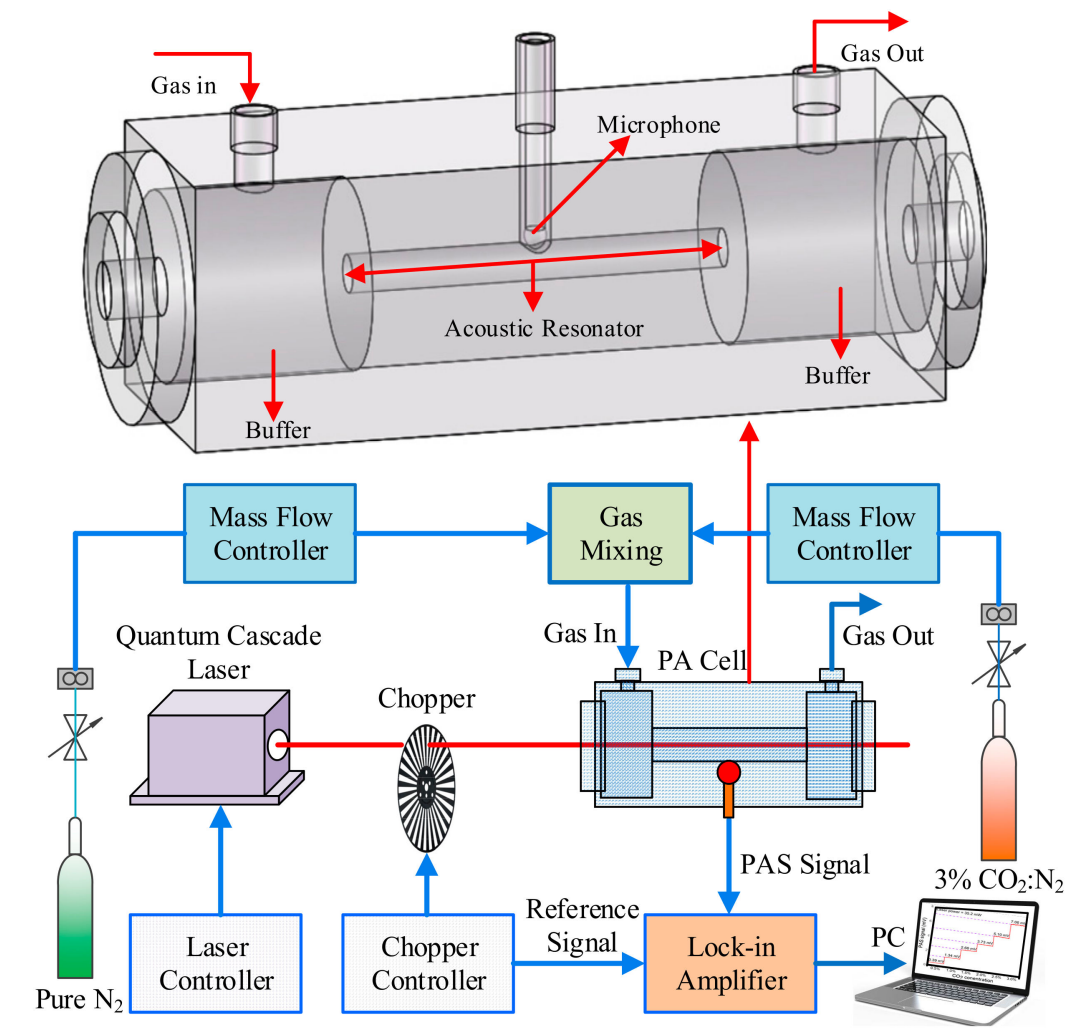

Figure 3. The Schematic of the photoacoustic spectroscopy (PAS) based $\mathrm{CO}_{2}$ sensor system with a FW-QCL.

\section{Results and Discussions}

The signal stability of the $\mathrm{CO}_{2}$-PAS sensor system was tested. The modulation frequency of the chopper was set at $1580 \mathrm{~Hz}$ to match the resonant frequency of the PA cell. The optical power of the FW-QCL was $35.2 \mathrm{~mW}$ with an injection current of $500 \mathrm{~mA}$. A 30,000 ppm gas mixture of $\mathrm{CO}_{2}$ and $\mathrm{N}_{2}$ was used. In order to test the stability of the sensor system, the PAS signal was detected with and without FW-QCL many times. The results of the tests are shown in Figure 4. It can be seen that with the same $\mathrm{CO}_{2}$ gas concentration, the signal amplitude of the $\mathrm{CO}_{2}-\mathrm{PAS}$ sensor could be maintained at the same level, which indicated an excellent sensor system stability. 


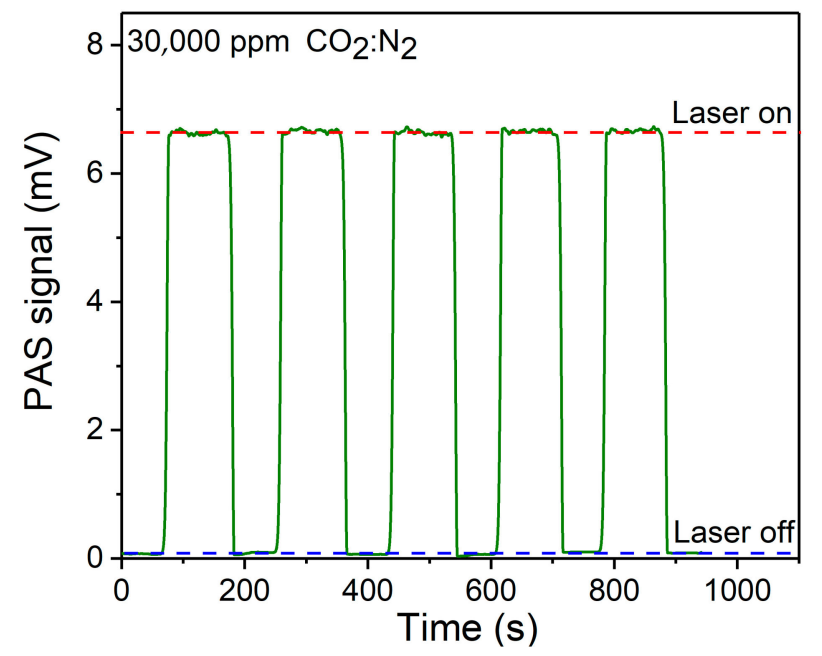

Figure 4. Signal stability of the reported FW-QCL based $\mathrm{CO}_{2}$ sensor system.

In order to verify the concentration response of the PAS based sensor system with a FW-QCL, the PAS signal was detected with different $\mathrm{CO}_{2}$ concentrations. At a standard atmospheric pressure, a 30,000 ppm $\mathrm{CO}_{2}-\mathrm{N}_{2}$ mixture was diluted with pure $\mathrm{N}_{2}$ using two mass flow controllers. The $\mathrm{CO}_{2}$ detection results are depicted in Figure 5a. It can be seen that the $\mathrm{CO}_{2}-\mathrm{PAS}$ signal increased with an increase of the gas concentration. Furthermore, the noise of the sensor system was measured when the PA cell was filled with pure dry $\mathrm{N}_{2}$. From the inset of Figure $5 \mathrm{a}$, it can be seen that with an integration time of $1 \mathrm{~s}$, the $1 \sigma$ background noise was $0.664 \mu \mathrm{V}$ and the $3 \sigma$ background noise was $1.991 \mu \mathrm{V}$. Therefore, the $1 \sigma$ and $3 \sigma$ minimum detection limit (MDL) of the PAS based sensor system with a fixed wavelength QCL for the detection of $\mathrm{CO}_{2}$ was $2.84 \mathrm{ppm}$ and $8.46 \mathrm{ppm}$, respectively. The PAS signal as a function of $\mathrm{CO}_{2}$ concentration is shown in Figure $5 \mathrm{~b}$. After a linear fitting routine was used, the obtained R-square was $\sim 0.99$, which means that the sensor system has an excellent linear response to gas concentrations

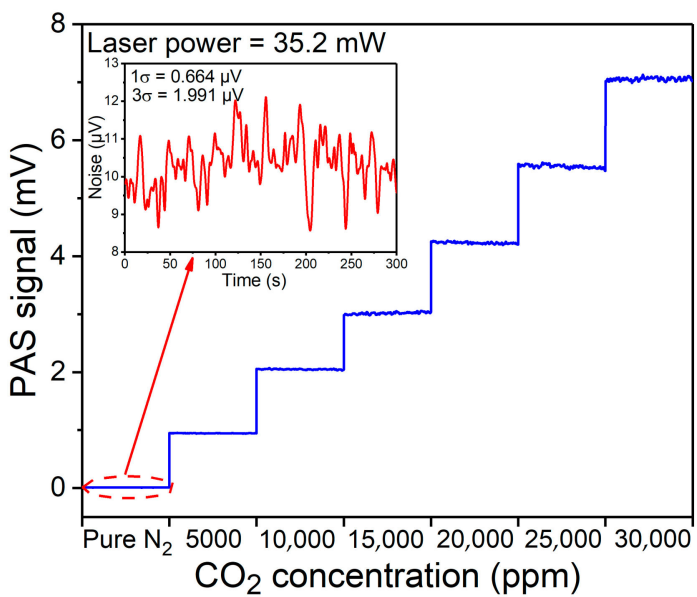

(a)

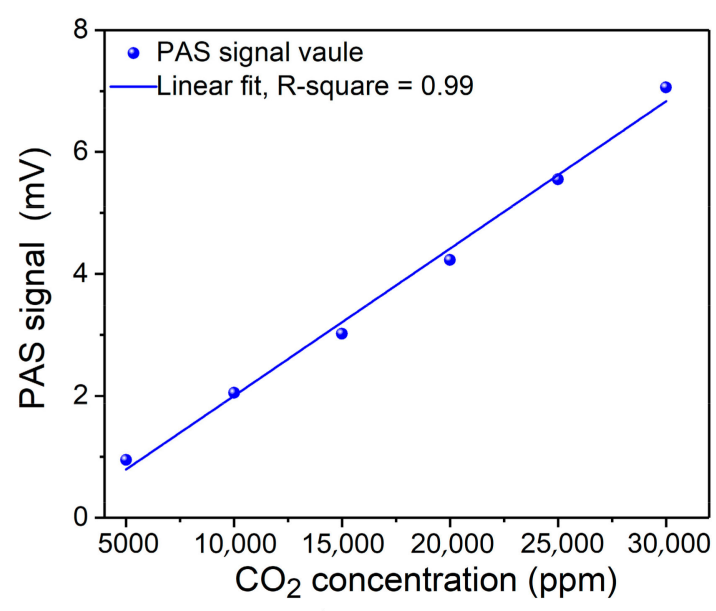

(b)

Figure 5. (a) System noise and PAS signal for different $\mathrm{CO}_{2}$ concentration levels. (b) PAS signal as a function of $\mathrm{CO}_{2}$ concentration.

The long-term stability of the reported sensor system was evaluated by means of an Allan deviation analysis. The Allan deviation shows the relationship between the system stability and the averaging time. Pure dry $\mathrm{N}_{2}$ was flushed into the PA cell with a constant flow. The PAS signal was measured for a three hours period. The result of this measurement is shown in Figure 6, where it can be seen that 
when the integration time was $\sim 100 \mathrm{~s}$, a MDL of $1 \mathrm{ppm}$ can be obtained. When the integration time was larger than $100 \mathrm{~s}$ system drifts start to dominate.

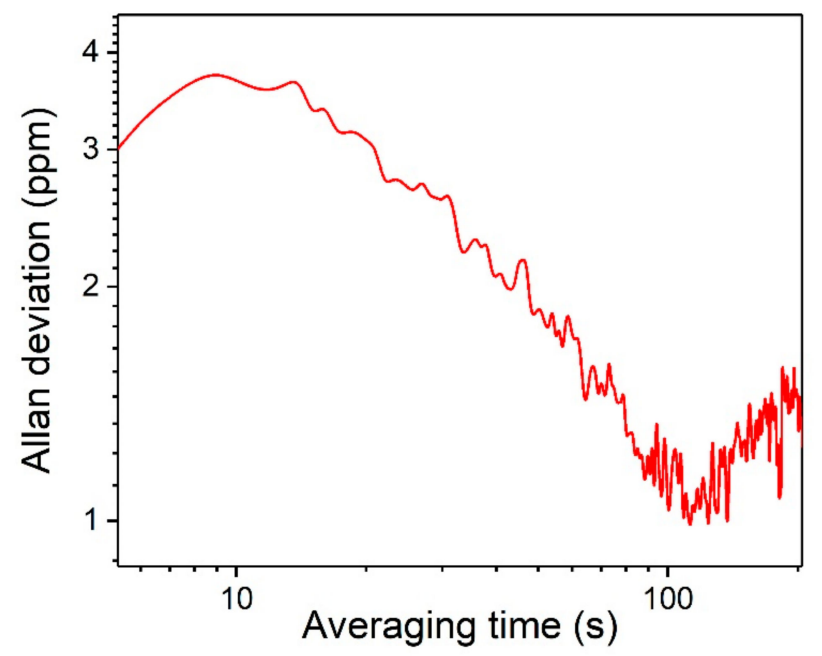

Figure 6. Allan deviation analysis for the FW-QCL based $\mathrm{CO}_{2}$ sensor system.

There are many sources of $\mathrm{CO}_{2}$ emissions in daily life, such as cigarette smoking, the exhaust from automobiles and the combustion of carbon-containing materials. The $\mathrm{CO}_{2}$ concentrations from these sources were much higher than the MDL of the reported PAS based $\mathrm{CO}_{2}$ sensor system. Therefore, it is possible to detect the $\mathrm{CO}_{2}$ concentration from these sources with the reported sensor system. In the measurements, an inlet tube was placed outside the laboratory and the atmospheric air was pumped into the $\mathrm{CO}_{2}$-PAS sensor. The measured results are shown in Figure 7. It can be seen that the atmospheric $\mathrm{CO}_{2}$ concentration level was $\sim 250 \mathrm{ppm}$ and that the emission levels from automobile exhaust are the highest.

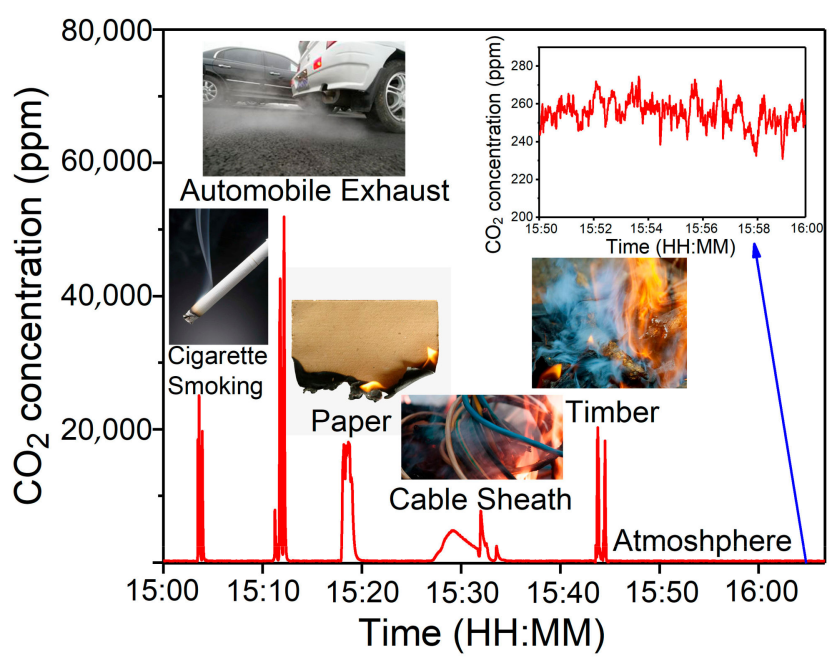

Figure 7. $\mathrm{CO}_{2}$ detection from several sources with the reported $\mathrm{QCL}$ based $\mathrm{CO}_{2}$ sensor system on the HIT campus, Harbin, China (Latitude and longitude are: $45^{\circ} 43^{\prime} \mathrm{N} / 126^{\circ} 37^{\prime} \mathrm{E}$ ).

\section{Conclusions}

In conclusion, a PAS based $\mathrm{CO}_{2}$ sensor using a FW-QCL was demonstrated in this manuscript. The laser was tuned to the desired wavelength by using a diffraction grating. Such a fixed wavelength (FW) configuration has the merits of easy design and is advantageous for application of the reported sensor system. The emission wavelength of the FW-QCL was set at $4.42 \mu \mathrm{m}$ in the mid-infrared region, 
which matched a fundamental $\mathrm{CO}_{2}$ absorption line and significantly improved the absorption intensity when compared to the overtone absorption band in the near-infrared region. A resonant PA cell with a resonant frequency of $1580 \mathrm{~Hz}$ was used to accumulate the acoustic energy. A mechanical chopper was employed to modulate the laser intensity. A correlation demodulation technique was used to reduce the noise from the background. When the integration time of the lock-in amplifier was set to $1 \mathrm{~s}$, a $1 \sigma \mathrm{MDL}$ of $2.84 \mathrm{ppm}$ for the detection of the $\mathrm{CO}_{2}$ was achieved. An Allan deviation analysis was applied to evaluate the long-term stability of the reported $\mathrm{CO}_{2}$ sensor. The results showed that when the integration time was $\sim 100 \mathrm{~s}$, a MDL of $1 \mathrm{ppm}$ can be obtained. This sensor was also used to measure the $\mathrm{CO}_{2}$ concentration from several common emission sources, such as cigarette smoking, automobile exhaust and the combustion of some carbon-containing materials. These measurements indicated the stability and robustness of the reported FW-QCL based $\mathrm{CO}_{2}$-PAS sensor system. With a high detection sensitivity and stability, this FW-QCL based $\mathrm{CO}_{2}$-PAS sensor is suitable for applications in industrial processing, environmental monitoring, and fire detection.

Author Contributions: Y.M. is the group leader and was involved in designing the experiment and revising the manuscript. S.Q. performed experiments and prepared this manuscript. Y.W. and Y.Hu were involved in data processing. Y.H., X.Y., Z.Z., and Y.Q. provided valuable guidance of the experiments. F.K.T. revised the manuscript. All authors were involved in numerous discussions related in all aspects of this paper.

Funding: This research was funded by National Natural Science Foundation of China (Grant No. 61875047 and 61505041), Natural Science Foundation of Heilongjiang Province of China (Grant No. YQ2019F006), Fundamental Research Funds for the Central Universities, Financial Grant from the Heilongjiang Province Postdoctoral Foundation (Grant No. LBH-Q18052).

Acknowledgments: Frank K. Tittel acknowledges grant C-0586 from the Welch Foundation.

Conflicts of Interest: The authors declare no conflict of interest.

\section{References}

1. Hashimoto, K. Global temperature and atmospheric carbon dioxide concentration. In Global Carbon Dioxide Recycling; Springer: Singapore, 2019; pp. 5-17.

2. Hoel, M.; Kverndokk, S. Depletion of fossil fuels and the impacts of global warming. Resour. Energy Econ. 1996, 18, 115-136. [CrossRef]

3. Schneider, S.H. The greenhouse effect: Science and policy. Science 1989, 243, 771-781. [CrossRef] [PubMed]

4. Hansen, J.; Johnson, D.; Lacis, A.; Lebedeff, S.; Lee, P.; Rind, D.; Russell, G. Climate impact of increasing atmospheric carbon dioxide. Science 1981, 213, 957-966. [CrossRef] [PubMed]

5. Doney, S.C.; Fabry, V.J.; Feely, R.A.; Kleypas, J.A. Ocean acidification: The other $\mathrm{CO}_{2}$ problem. Annu. Rev. Mar. Sci. 2009, 1, 169-192. [CrossRef]

6. Chakraborty, S.; Tiedemann, A.V.; Teng, P.S. Climate change: Potential impact on plant diseases. Environ. Pollut. 2000, 108, 317-326. [CrossRef]

7. Tam, A.C. Applications of photoacoustic sensing techniques. Rev. Mod. Phys. 1986, 58, 381. [CrossRef]

8. Harren, F.J.M.; Mandon, J.; Cristescu, S.M. Photoacoustic Spectroscopy in Trace Gas Monitoring; John Wiley \& Sons Ltd.: Chichester, UK, 2000; pp. 2203-2226.

9. Hernández-Aguilar, C.; Domínguez-Pacheco, A.; Cruz-Orea, A.; Ivanov, R. Photoacoustic spectroscopy in the optical characterization of foodstuff: A review. J. Spectrosc. 2019, 2019, 34. [CrossRef]

10. Popa, C. Breathing disorders using photoacoustics gas analyzer. J. Med. Imaging Health Inf. 2016, 6, $1893-1895$. [CrossRef]

11. Ma, Y.F. Review of recent advances in QEPAS-based trace gas sensing. Appl. Sci. 2018, 8, 1822. [CrossRef]

12. Wu, H.P.; Dong, L.; Yin, X.K.; Sampaolo, A.; Patimisco, P.; Ma, W.G.; Zhang, L.; Yin, W.B.; Xiao, L.T.; Spagnolo, V.; et al. Atmospheric $\mathrm{CH}_{4}$ measurement near a landfill using an ICL-based QEPAS sensor with V-T relaxation self-calibration. Sens. Actuators B Chem. 2019, 297, 126753. [CrossRef]

13. Patimisco, P.; Sampaolo, A.; Dong, L.; Tittel, F.K.; Spagnolo, V. Recent advances in quartz enhanced photoacoustic sensing. Appl. Phys. Rev. 2018, 5, 011106. [CrossRef] 
14. Yin, X.; Dong, L.; Wu, H.P.; Zheng, H.D.; Ma, W.G.; Zhang, L.; Yin, W.B.; Jia, S.T.; Tittel, F.K. Sub-Ppb nitrogen dioxide detection with a large linear dynamic range by use of a differential photoacoustic cell and a $3.5 \mathrm{~W}$ blue multimode diode laser. Sens. Actuators B Chem. 2017, 247, 329-335. [CrossRef]

15. Liu, K.; Mei, J.X.; Zhang, W.J.; Chen, W.D.; Gao, X.M. Multi-resonator photoacoustic spectroscopy. Sens. Actuators B Chem. 2017, 251, 632-636. [CrossRef]

16. Erfanzadeh, M.; Kumavor, P.D.; Zhu, Q. Laser scanning laser diode photoacoustic microscopy system. Photoacoustics 2018, 9, 1-9. [CrossRef]

17. Popa, C. Detection of ethylene traces by infrared spectroscopy in mental disorders. Rom. Rep. Phys. 2015, 67, 1565-1569.

18. Popa, C. Infrared spectroscopy study of the influence of inhaled vapors/smoke produced by cigarettes of active smokers. J. Biomed. Opt. 2014, 20, 051003. [CrossRef]

19. Elia, A.; Lugarà, P.M.; Di Franco, C.; Spagnolo, V. Photoacoustic techniques for trace gas sensing based on semiconductor laser sources. Sensors 2009, 9, 9616-9628. [CrossRef]

20. Ma, Y.F.; Qiao, S.D.; He, Y.; Li, Y.; Zhang, Z.H.; Yu, X.; Tittel, F.K. Highly sensitive acetylene detection based on multi-pass retro-reflection-cavity-enhanced photoacoustic spectroscopy and a fiber amplified diode laser. Opt. Express 2019, 27, 14163-14172. [CrossRef]

21. He, Y.; Ma, Y.F.; Tong, Y.; Yu, X.; Peng, Z.F.; Gao, J.; Tittel, F.K. Long distance, distributed gas sensing based on micro-nano fiber evanescent wave quartz-enhanced photoacoustic spectroscopy. Appl. Phys. Lett. 2017, 111, 24110. [CrossRef]

22. Yi, H.M.; Maamary, R.; Gao, X.M.; Sigrist, M.W.; Fertein, E.; Chen, W.D. Short-lived species detection of nitrous acid by external-cavity quantum cascade laser based quartz-enhanced photoacoustic absorption spectroscopy. Appl. Phys. Lett. 2015, 106, 101109. [CrossRef]

23. Ma, Y.F.; He, Y.; Zhang, L.G.; Yu, X.; Zhang, J.B.; Sun, R.; Tittel, F.K. Ultra-high sensitive acetylene detection using quartz-enhanced photoacoustic spectroscopy with a fiber amplified diode laser and a $30.72 \mathrm{kHz}$ quartz tuning fork. Appl. Phys. Lett. 2017, 110, 031107. [CrossRef]

24. Qiao, S.D.; Ma, Y.F.; He, Y.; Yu, X.; Zhang, Z.H. A sensitive carbon monoxide sensor based on photoacoustic spectroscopy with a $2.3 \mu \mathrm{m}$ mid-infrared high-power laser and enhanced gas absorption. Sensors 2019, 19, 3202. [CrossRef]

25. Liu, K.; Cao, Y.; Wang, G.S.; Zhang, W.J.; Chen, W.D.; Gao, X.M. A novel photoacoustic spectroscopy gas sensor using a low cost polyvinylidene fluoride film. Sens. Actuators B Chem. 2018, 277, 571-575. [CrossRef]

26. Karpf, A.; Qiao, Y.H.; Rao, G.N. Ultrasensitive, real-time trace gas detection using a high-power, multimode diode laser and cavity ringdown spectroscopy. Appl. Opt. 2016, 55, 4497-4504. [CrossRef]

27. Tomberg, T.; Vainio, M.; Hieta, T.; Halonen, L. Sub-parts-per-trillion level sensitivity in trace gas detection by cantilever-enhanced photo-acoustic spectroscopy. Sci. Rep. 2018, 8, 1848. [CrossRef]

28. Kosterev, A.A.; Tittel, F.K. Chemical sensors based on quantum cascade lasers. IEEE J. Quantum Elect. 2002, 38, 582-591. [CrossRef]

29. Faist, J.; Capasso, F.; Sivco, D.L.; Sirtori, C.; Hutchinson, A.L.; Cho, A.Y. Quantum Cascade Laser. Science 1994, 5158, 553-556. [CrossRef]

30. Gmachl, C.; Capasso, F.; Sivco, D.L.; Cho, A.Y. Recent progress in quantum cascade lasers and applications. Rep. Prog. Phys. 2001, 64, 1533. [CrossRef]

31. Schjolberg-Henriksen, K.; Schulz, O.; Ferber, A.; Moe, S.; Lloyd, M.; Muller, G.; Suphan, K.; Wang, D.T.; Bernstein, R.W. Sensitive and selective photoacoustic gas sensor suitable for high-volume manufacturing. IEEE Sens. J. 2008, 8, 1539-1545. [CrossRef]

32. Schulz, O.; Legner, W.; Müller, G.; Schjølberg-Henriksen, K.; Ferber, A.; Moe, S.; Lloyd, M.H.; Suphan, K.H. Photoacoustic Gas Sensing Microsystems. In Proceedings of the 13th International SENSOR Conference 2007, Nürnberg, Germany, 22-24 May 2007.

33. Spannhake, J.; Helwig, A.; Schulz, O.; Müller, G. Micro-fabrication of gas sensors. In Solid State Gas Sensing; Comini, E., Faglia, G., Sberveglieri, G., Eds.; Springer: Boston, MA, USA, 2009; pp. 1-46.

34. Scholz, L.; Perez, A.O.; Knobelspies, S.; Wöllenstein, J.; Palzer, S. MID-IR LED-based, Photoacoustic $\mathrm{CO}_{2}$ Sensor. Procedia Eng. 2015, 120, 1233-1236. [CrossRef]

35. Eberl, M.; Jost, F.; Kolb, S.; Schaller, R.; Dettmann, W.; Gassner, S.; Skorupa, F. Miniaturized photoacoustic $\mathrm{CO}_{2}$ gas sensors-A new approach for the automotive sector. In Proceedings of the AmE 2019-Automotive meets Electronics, 10th GMM-Symposium, Dortmund, Germany, 12-13 March 2019; pp. 1-5. 
36. Ma, Y.F.; Lewicki, R.; Razeghi, M.; Tittel, F.K. QEPAS based ppb-level detection of $\mathrm{CO}$ and $\mathrm{N}_{2} \mathrm{O}$ using a high power CW DFB-QCL. Opt. Express 2013, 21, 1008-1019. [CrossRef] [PubMed]

37. Gordon, I.E.; Rothman, L.S.; Hill, C.; Kochanov, R.V.; Tan, Y.; Bernath, P.F.; Birk, M.; Boudon, V.; Campargue, A.; Chance, K.V.; et al. The HITRAN 2016 molecular spectroscopic database. J. Quant. Spectrosc. Radiat. Transf. 2017, 203, 3-69. [CrossRef] 